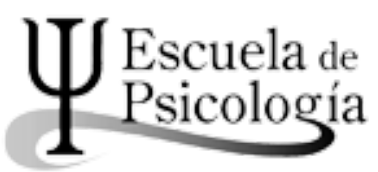

Wímblu, Rev. estudiantes Esc. de psicología, Univ. de Costa Rica. 12 (2): 77-86, 2017 / ISSN: 1659-2107

\title{
Egoyan y Freud: construcciones intermediales en cine
}

\author{
Egoyan and Freud: intermedial constructions in cinema
}

\author{
Lic. Kira Schroeder Leiva*
}

\begin{abstract}
Resumen: Este trabajo relaciona intermedialidad y psicoanálisis a partir de la película Ararat, del director Atom Egoyan. La película se basa en un cuadro del pintor Arshile Gorki, pintor estadounidense de origen armenio, que intenta reinventarse en Estados Unidos después de haber sobrevivido el genocidio de su pueblo. La autora argumenta que los recursos utilizados por el cineasta para construir la historia detrás del cuadro del pintor y su madre, tienen su paralelo en los recursos que Freud utiliza para reconstruir el origen de las fantasías congeladas de sus pacientes. El arte y el psicoanálisis ambos, entonces, encuentran la necesidad de hechar mano de varios medios, y los espacios donde intersectan, para reconstruir la historia.
\end{abstract}

Palabras clave: Intermedialidad, psicoanálisis, cine, Atom Egoyan, Sigmund Freud, Arshild Gorki.

Abstract: This paper relates intermediality and psychoanalysis through the movie Ararat, directed by Atom Egoyan. The film is based on a portrait by Arshile Gorki, a US paintor of Armenian origin who tries to reinvent himself after having survived the genocide of his people. The author argues that the resources used by the film-maker to construct the history behind the portrait of the paintor and his mother, have a parallel in the resources used by Freud in order to reconstruct the origin of the frozen fantasies told by his patients. Art and psychonalysis both, find the need to take advantage of serveral mediums, and the spaces where they intersect, in order to reconstruct history.

Key Words: Intermediality, psychoanalysis, film, Atom Egoyan, Sigmund Freud, Arshild Gorki.

* Universidad de Costa Rica. Docente Escuela de psicología.

Correo electrónico: kiraschroederleiva@gmail.com

1. El presente manuscrito fue elaborado en un curso dictado por la Dra. Karen Poe en la Maestría en Artes de la Universidad de Costa Rica, a ella mi agradecimiento por su transmisión. El trabajo fue presentado en el III Coloquio de cine, literatura y otras relaciones intermediales, llevado a cabo en la Universidad de Costa Rica el 29, 30, y 31 de Octubre 2014. 
Para introducir este ensayo sobre la película Ararat (Egoyan \& Lantos, \& Egoyan, 2002) encuentro necesario decir algo de la historia personal de su director Atom Egoyan y de la historia de su herencia armenia ${ }^{1}$. La mejor manera de comenzar entonces es darle lugar a las palabras de Egoyan,

Mis abuelos por parte de mi padre fueron víctimas de los horrores que sufrió la población armenia de Turquía en los años alrededor de 1915. Mi abuelo, cuya familia entera excepto su hermana fue borrada en las masacres, se casó con mi abuela, la única sobreviviente de su familia. Yo nunca los conoci. Ambos murieron mucho antes de que naciera. (Egoyan citado en Wilson, 2009, p. 119)2

Lo que hoy conocemos como la diáspora Armenia, son comunidades alrededor del mundo que de una u otra manera sobrevivieron o huyeron del genocidio armenio o Medz Yeghern, donde murieron aproximadamente 1 millón de personas de una población de 2 millones de armenios, que se calcula vivían como ciudadanos del Estado Otomán antes de 1915. Bajo la figura de las deportaciones, estas personas fueron horrorosamente masacradas y violadas, y muchos murieron de inanición. Cuando el Imperio Otomano fue reemplazado por la República de Turquía, el nuevo Estado se negó a admitir que el genocidio hubiese ocurrido y hasta el día de hoy lo niegan a pesar de que los historiadores e instituciones internacionales como la ONU lo reconocen abiertamente.

La película Ararat es definida de la manera más clara a mi parecer por Emma Wilson en su libro sobre Atom Egoyan, al decir que es "una investigación de la imposibilidad de hacer una película sobre el genocidio" $\left(2009\right.$, p. xi) ${ }^{3}$. Intentaré por medio de este escrito estudiar uno de los recursos interpretativos utilizados por Egoyan en esa investigación, desde un punto de vista intermedial y psicoanalítico.

La presentación en dvd de la película Ararat trae un segundo disco llamado "Beyond Ararat" ("Más allá de Ararat") que incluye varios videos y recursos referentes a la película. Entre ellos me llamó poderosamente la atención una pequeña película llamada "Retrato de Arshile" (1995), producto de una invitación que se le hizo a Egoyan a reflexionar sobre una obra de arte. El Arshile retratado en el film, es el pequeño hijo de Atom Egoyan y su esposa Arsince Khajian, cuyo nombre fue escogido en alusión al pintor Arshile Gorki, sobreviviente del genocidio armenio llevado a cabo por los turcos. Conforme vemos imágenes de su hijo, Egoyan explica que el filme es un intento de dar cuenta a su hijo del origen de su nombre, dice "La pintura tuvo un gran impacto en mi" (Griffiths \& Freeman, \& Egoyan, 1995, 00:00:37) ${ }^{4}$, refiriéndose a Retrato del pintor y su madre de Gorki. Ese impacto se tradujo en su film Ararat, y el director relata que el personaje del pintor armenio le parece enigmático por su intento de reinventarse una vez emigrado a Estados Unidos, donde cambia su nombre Vostanik Manoog Adoyan por Arshile Gorki, según Egoyan como "una manera de enfrentarse al trauma y la identidad" (Griffiths \& Freeman, \& Egoyan, 1995, 00:01:55) ${ }^{5}$. Al final de este corto, Egoyan nos ofrece su particular versión del concepto de intermedialidad utilizando el cuadro de Gorki, versión que es sin duda el punto de partida de Ararat. Nos muestra una secuencia de imágenes: primero una foto del pintor y su madre tomada antes del genocidio, luego el bosquejo hecho por el pintor en una cuadrícula en preparación para la elaboración del cuadro, y luego una de las dos versiones de Retrato del pintor y su madre, la que se encuentra en la Galería Nacional de Arte en Washington D.C. ${ }^{6}$ Conforme muestra la secuencia de imágenes se escucha su voz describiéndolas y dice "una imagen siendo transpuesta de un medio a otro" (Griffiths \& Freeman, \& Egoyan, 1995, 00:03:27).

La palabra [transpose] en inglés tiene la acepción relacionada con la música que significa transportar o escribir una pieza musical escrita en un cierto tono, a otro. Me parece que esta acepción es la que mejor calza con este estilo intermedial de Egoyan, ya que en esta transposición de un tono a otro, algo se pierde de la pieza original y algo nuevo se produce, lo mismo podemos decir del paso de la foto, al bosquejo, y finalmente al cuadro.

Me interesa aquí apuntar que del filme Retrato de Arshile, al filme Ararat, se incluyen tres imágenes más en esta secuencia intermedial, una al principio, otra entre el bosquejo y el cuadro, y otra al final. En Ararat se hace referencia a la imagen de la madona y el niño esculpida en las paredes de la Catedral de la Santa Cruz, iglesia armenia que se encuentra en la isla de Ahtamar en el lago de Van. En la película se propone que esa imagen es una imagen primera que inspiró el cuadro de Gorki.

En una escena que retrata a Gorki en el proceso de pintar el cuadro el cual le tomó 10 años terminar -, avanzado ya el retrato, y dolorosamente perseguido por el fantasma de la muerte de su madre en el genocidio, el pintor cubre sus manos de pintura y con ellas borra las manos de su madre. Esta escena resuelve una discusión presente en el filme que debate si el cuadro quedó inacabado o si más bien las manos fueron borradas, en ambos casos esta particularidad de la pintura es relacionada a la forma en que la historia y la cultura han evitado mencionar o han reprimido el genocidio armenio. Se adiciona entonces esta escena a la secuencia intermedial de imágenes, ubicándose entre el bosquejo y el cuadro.

Quisiera ahora argumentar que la película Ararat, como creación de Egoyan estaría ubicándose en el último lugar de la secuencia intermedial inicialmente propuesta por él mismo en Retrato de Arshile, y replanteada en el film de 2002. En el corto Egoyan hace un lapsus, dice lo siguiente: "Dos versiones de este cuadro existen. Una está en el Museo Whitney, que es la que usamos en la pintura, perdón, la que usamos en el film..." (Griffiths \& Freeman, \& Egoyan, 1995, 00:03:39) ${ }^{8}$

Si tomo a Freud y su lectura de los equívocos a la letra, me atrevo a proponer que Egoyan pintó Ararat y que su pintura vendría a colocarse como una reelaboración de Retrato del artista y su madre en otro tono, o una transposición del cuadro de Gorki en tono fílmico. 
Esta inserción que hace Egoyan de tres elementos intermediales que resignifican la primera secuencia presentada en Retrato de Arshile parecen dar una respuesta a la pregunta propuesta en ese mismo corto a partir de la foto que inspira el cuadro de Arshile Gorki. Egoyan dice:

pero por supuesto, de manera más significativa en cierto punto nos movemos a la noción de la fotografía que es la base de Ararat. La fotografía de Arshile Gorki y su madre, que fue tomada en Ven y es una fotografía muy espiritual para mi porque de cierta manera esta imagen que fue tomada antes del genocidio vendría a perseguir sork a sino que pienso que a la conciencia de los armenios... (1995, $00: 02: 47)^{9}$

La pintura de Gorki parece articular para Egoyan la pregunta por un origen violento y reprimido por mucho tiempo de la historia oficial, que según él retorna, diría yo como el fantasma del padre de Hamlet, a reclamar un acto. Propongo que Egoyan responde con un acto de lectura que es Ararat. Así lo confirman los relatos del Making of Ararat, donde por ejemplo el productor de Ararat Robert Lantos dice,

este es un film que no es sólo un film, tiene una misión y la misión es llenar un espacio en blanco, poner ahi en la pantalla para siempre, un crimen que tarde o temprano tiene que ser reconocido, pero que por el momento no tiene paternidad admitida... (Egoyan \& Lantos, \& Francis, 2003, 00:02:46)

Este acto de lectura, tiene una textura intermedial, como ya argumenté al principio de este escrito, pero además un movimiento retroactivo o una construcción, tal y como encontramos en dos escritos freudianos en donde el autor se coloca como lector de una imagen enigmática.

En Pegan a un niño, texto de 1919, Freud relata que seis pacientes neuróticos confiesan con dificultad una fantasía en la cual presencian que un niño es azotado, fantasía acompañada de satisfacciones sexuales onanistas, que genera mucha culpa y vergüenza. Freud nos hace la aclaración de que en las historias de vida de estos pacientes no hay señales de que sus padres hayan recurrido a la violencia para su educación. Nos informa además, que al interrogar a sus pacientes sobre el contenido de la fantasía, estos no pueden asociar, y contestan no saber los detalles de la escena, la identidad del niño, su género, o la identidad de quien azota, solamente tienen seguridad de que un niño es azotado. Freud construye el recorrido para llegar a la articulación congelada "pegan a un niño", nos dice, "Pudieran, pues, tener muy bien una prehistoria, haber realizado una evolución y corresponder a un desenlace y no a un principio" (1919, p. 2468) y a través de este recorrido varía su contenido, los personajes que participan y su significación. En una primera fase que se corresponde a la temprana infancia, el niño azotado no es la paciente, y el que azota es una figura paterna. Este primer momento tiene que ver con la agresividad que genera el tener que compartir el amor de los padres con los hermanos, entonces Freud la articula en la siguiente frase "el padre pega al niño odiado por mí" (p. 2468). En la segunda fase el cambio se da en quien es objeto de los azotes, el niño conjuga en ella la culpa por haber odiado a la hermana y el deseo por el progenitor, adquiriendo esta un matiz masoquista y se articula "yo soy golpeado por mi padre" (p. 2469). Freud encuentra necesario construir esta segunda fase, ahí donde el paciente no puede recordarla. La tercera fase es muy similar a la primera, pero la diferencia radica en que va a acompañada de una excitación sexual de carácter onanista, y que la imagen del padre es sustituida por un equivalente simbólico, como por ejemplo un profesor.

En la clase del 16 de enero de 1957 del Seminario 4, titulado La relación de objeto, Lacan está trabajando su concepto de fantasma ${ }^{11}$ alrededor del texto freudiano del que hablamos, y enfatiza la articulación tripartita de la escena relatada en la fantasía "pegan a un niño", al respecto dice, "La situación fantasmática tiene la manifiesta complejidad de constar de tres personajes, está el agente del castigo, está el que lo sufre y está el sujeto" (1956-1957, p. 42). Lo interesante de subrayar aquí es que el sujeto es inicialmente testigo de la escena, luego el que recibe los azotes, y también director de la escena, diríamos el que mueve la mano del azotador. La escena fantasmática permite la circulación del sujeto-director de la escena a través de los personajes que la componen, lo cual quiere decir que está ahí implicado tanto como sujeto y objeto de un goce masoquista-sadista ${ }^{12}$, tal y como se puede desprender de la fórmula del fantasma propuesta por Lacan "\$ <> a", donde se muestra en su mínima expresión la implicación subjetiva en la escena. De esta manera la construcción retroactiva de momentos lógicos a partir de "un niño es azotado" que nos propone Freud, permite el despliegue de una escena de goce, con los posibles lugares a ser ocupados y los celos, odios, amores y venganzas que en ella se juegan.

Retornemos a Ararat, en una entrevista con Geoff Pevere, Egoyan dice

Para mi, el logro más alto de cualquier film es el de entrar tan completamente en el subconsciente del espectador que hay momentos y escenas y gestos que pueden ser generados por la imaginación del espectador. Que se convierte en parte del film que están pasando en su mente. (Pevere citado en Wilson, 2009, p, 5) ${ }^{13}$

No es de extrañarse que en Ararat, Egoyan nos invita a inmiscuirnos en su lectura de la pintura de Gorki, internarnos en las múltiples historias contenidas en Ararat que se desprenden de Retrato del pintor y su madre, con sus capas de odio, amor, erotismo, venganza, deseos incestuosos, muerte e intentos de encontrar el sentido de un origen. Tal como Freud se pregunta por la escena fantasmática de "pegan a un niño", Egoyan se coloca frente al cuadro de Gorki, y ambos nos colocan a nosotros espectadores como ese sujeto que mira la escena en un lugar de director-voyerista. Desde ese lugar Egoyan nos pasea por los caminos retorcidos de su lectura del cuadro, guiado por la pregunta que esta pintura le 
arroja, ¿Qué hacer como armenios contemporáneos con el saber del genocidio y su borramiento de la historia oficial? El film propone varias respuestas: Gorki, primera generación de sobrevivientes, no soportó vivir con el doloroso recuerdo y se suicidó; el papá de Raffi - personaje principal del film- murió en el intento de asesinar a un diplomático turco; Ani, la profesora universitaria, escribe un libro de historia del arte sobre Gorki para recordar y reivindicar su vida y obra; Raffi regresa a la tierra perdida para encontrar respuestas contenidas en su cámara pero que a pesar de eso se le escapan; Saroyan ${ }^{14}$ el director del film dentro del film, hace una película sobre la tragedia que vivió y sobrevivió su madre, para escribir una terrible historia olvidada, cuyo recuerdo vive en la diáspora armenia.

Esta última respuesta es un mise en abyme, que propone una duplicación del lugar de Egoyan frente a Ararat, dirigir una película sobre un director de ascendencia armenia que hace una película sobre el genocidio armenio. La puesta en abismo le permite un distanciamiento necesario para poder sostener la inevitable ficcionalidad de una verdad imposible de decir, que de todas maneras y por su misma imposibilidad intenta sacar a la luz. En la película hay varias escenas que replican este distanciamiento: por ejemplo una escena inicia mostrando el relato que cuenta la película dentro de la película, y de pronto un movimiento de cámara nos muestra las afueras del set y el dolor en los ojos del director Saroyan; o la perturbada mirada de Raffi mirando la grabación de una escena; o a Ani irrumpiendo en el set donde se está desarrollando una escena especialmente dolorosa, mostrándonos como los límites de la puesta en abismo se desdibujan. Como si el doloroso pasado atravesara como un fantasma ${ }^{15}$ la vida de los personajes, insinuando que lo mismo pudo ocurrir con las personas involucradas con Egoyan en la elaboración de Ararat. Al igual que Gorki, Egoyan responde a la pregunta por el legado del genocidio con arte, con un acto artístico, con una pintura fílmica. Este acto mediatizado a través del cine, adquiere su carácter trasgresor al nombrar un goce ${ }^{16}$ en el cual el artista está implicado, y por lo tanto nombrarlo, representarlo, significa un corte. Este acto corta un lazo social de complicidad en el goce, y la obra artística, su producto, se convierte en invitación a un lazo social otro.

En otro texto freudiano de 1914, El Moisés de Miguel Ángel podemos encontrar esta construcción retroactiva de la que hablábamos en Pegan a un niño, solamente que esta vez no se trata de fantasías descritas por los pacientes de Freud, sino de una escultura que fascinaba a Freud. La coincidencia entre el texto clínico y el texto artístico está quizá en que las fantasías se comportaban tan inamovibles como el mármol ante los intentos de Freud de poner a sus pacientes a asociar a partir de ellas. Según Poe (2016) la respuesta de Freud ante la inmovilidad de la estatua y la fuerza de la perturbación que ella le causaba es cinematográfica, "...Freud, aunque de manera rudimentaria, utiliza una técnica cinematográfica -el montaje- para introducir la dimensión temporal. Es decir que obliga a las ilustraciones y a la escultura a convertirse en una forma primitiva de cine" (p. 121).

Estas ilustraciones habían sido hechas por un dibujante contratado por Freud para plasmar su lectura retroactiva:

Me he hecho confeccionar, de manos de un artista, tres esbozos (figuras 1, 2, y 3) para ilustrar mi descripción. El tercero muestra la estatua tal como la vemos; los otros dos figuran los estadios previos que mi interpretación postula: el primero, el del reposo; el segundo, el de la suprema tensión, el apronte para levantarse de de estas. (Freud, 1914, p. 219)

Esta lectura retroactiva de Freud resulta más cercana a la hecha por Egoyan en su lectura de la pintura de Gorki en dos sentidos. Por un lado por ser el texto a leer un texto no literario - la estatua de Miguel Ángel y la pintura de Gorki - y por otro, al recurrir a otros medios o universos significantes para su elaboración. Aunque todas se presentan dentro del medio fílmico las imágenes presentadas por Egoyan provienen de otras texturas. La primera escena que Egoyan ubica dentro de su secuencia intermedial es una imagen de la Madonna y el bebé esculpida en piedra, luego una fotografía, luego un bosquejo, luego un cuadro, y luego un film dentro de un film. Como Freud, Egoyan reconoce la limitación de un universo simbólico para representar su lectura, y recurre a otros medios para construir la secuencia lógica que lleva a la imagen congelada en la pintura. Este movimiento intermedial no era ajeno a Freud, acostumbrado a la ardua y poética labor de traducir las imágenes de sus sueños en palabras, para luego reconocer ahí esbozos de sus deseos inconscientes ${ }^{17}$.

Sobre la relación entre Freud y la estatua de Moisés dice Poe,

Además de una lectura atenta a detalles insignificantes y apegada a la postura de cuerpo, Freud se detiene sobre un trazo imaginario, sobre la huella del movimiento de la mano sobre la barba, es decir, sobre algo que no está presente en la escultura, pero que al ponerla en movimiento es posible inferir. Con lo cual parece quere potencia de su influjo, ponerse a resguardo para captar su secreto y leer más allá de... (2016, p. 129)

Esto mismo me atrevería a decir sobre Egoyan frente a la pintura de Gorky, donde el más allá resulta en un movimiento retroactivo que historiza el texto artístico y lo renueva en su pluralidad de sentidos, transformando la pintura y transformando a su lector. Esta pluralidad de sentidos requiere ser expresada en diferentes tonos artísticos, porque el rango de uno no alcanza para decirse, y en sus bordes sus notas se escuchan mejor. En la película de Egoyan las distintas texturas de la imposibilidad de representar un genocidio, se tornan trozos de piedra, trazos en un papel, pinceladas más tarde borradas, retratos melancolizados, y también un film, uno que es además, pintura intermedial y acto artístico. 


\section{Notas}

1. Entiendo los peligros de esta introducción, los de caer en la psicologización de una producción artística a partir de la biografía de su autor. He tenido mucho cuidado de que este trabajo no se inoportuno y oportunista, y espero que quien lo lea encuentre la marca de mi esfuerzo.

2. Cita original: "My grandparents from my father's side were victims of the horrors that befell the Aremenian population of Turkey in the years around 1915. My grandfather, whose entire family save his sister was wiped out in the massacres, married my grandmother who was the sole survivor of her family. I never knew either of these people. They had both died long before
I was born". Traducción de Schroeder.

3. Cita original: "an investigation of the impossibility of making a film about genocide". Traducción de Schroeder

4. Cita original: "The painting had a great impact on me". Traducción de Schroeder.

5. Cita original: "as a way to deal with trauma and identity". Traducción de Schroeder.

6. Es importante recordar que con esas tres imágenes comienza la película Ararat. Traducción de Schroeder.

7. Cita original: "an image being transposed from one medium to another". Traducción de Schroeder.

8. Cita original: "Two versions of this painting exist. One is at the Whitney Museum, which is the one that we used in the painting, sorry the one that we used in the film..." Traducción de the one that
Schroeder.

9. Cita original: "... but of course, most significantly at a certain point we move to this notion of the photograph which is at the basis of Ararat. The photograph of Arshile Gorki and his mother which was taken in Ven and its a very spiritual photograph for me because in a way that image which was taken before the genocide would come back to haunt not

10. Cita original: "...this is a film that is not just a film, it has a mission and the mission is to fill in a blank, to put there on the screen forever, a crime that sooner or later has to be acknowledged but that for now it has no admitted paternity...". Traducción de Schroeder.

11. El concepto de fantasma es planteado por Lacan como la respuesta subjetiva a la pregunta por el deseo del Otro. La siguiente cita del Seminario 4 ayuda a su comprensión: "Lo importante es que aquí nos acercamos al inicio de una perspectiva histórica que es retroactiva. El sujeto formula [sic] y organiza una situación primitiva dramática a partir del punto en que nos encontramos en el analisis, de una forma que se inscribe en su palabra actual y su poder de simbolización presente. Asl, con el progreso del análisis nos encontramos con algo que se presenta como la cosa primitiva, la organización primordial más profunda" (1956-1957, p. 42). del vacío marcado por la falta en ser.
12. Escojo no utilizar el referente generalizado "sado-masoquista" para sostener el planteamiento de que lo primordial en el sujeto es el masoquismo al ser violentado o tomado por el significante.

13. Cita original: "To me, the highest aim of any film is to enter so completely into the subconscious of the viewer that there are moments and scenes and gestures which can be generated by Tha spectín des schroination. Traducción de Schroeder.

14. Nótese la homofonía entre Egoyan y Saroyan

15. Aquí, y en otros lugares del texto juego con la discusión alrededor de la palabra en francés usada por Lacan "Fantasme", retomada en relación al término en alemán utilizado por Freud "Phantasieren", segun algunos equivocamente traducido al español como fantasma, palabra que hace referencia más a una aparición proveniente de la muerte, que a una fantasía. En inglés se usa "fantasy" y no "ghost", pero quise poner en uso el equivoco de la traducción al español, pensando en la figura del fantasma del padre de Hamlet que Lacan problematiza en su trabajo sobre el deseo, y retomando lo dicho por Egoyan de que la foto de Gorky con genocidio, que a su vez es una imagen cristalizada en la pintura de Gorky.

16. Goce es la traducción del término utilizado por Lacan en francés jouissance, es difícil de definirlo porque precisamente nombra algo que constantemente escapa a la simbolización, pero puede pensarse como un disfrute doloroso en el cuerpo más allá del placer, tiene una connotación sexual y corporal, un ejemplo útil es la extraña satisfacción que el sujeto obtiene de su sintoma, la estructura simbólica es a su vez portadora de la imposibilidad del goce, y en "Diccionario introductorio de psicoanálisis Lacaniano" de Dylan Evans.

17. La técnica de interpretación de sueños freudiana puede ser considerada un écfrasis, tal y como into the domains of the visible" (Pethó, 2010, p. 212).

\section{Referencias bibliográficas}

Ágnes, P. (2010). Media in the Cinematic Imagination: Ekphrasis and Poetics of the In-Between in Jean-Luc Godard's Cinema in Media Borders, Multimodality and Intermediality. New York: MACMILLAN.

Dylan, E. (1997). Diccionario introductorio de psicoanálisis Lacaniano. Buenos Aires: Editorial Paidós.

Freud, S. (1914/1980). "El Moisés de Miguel Ángel". En Obras Competas, Tomo XIII. Buenos Aires: Amorrotu.

Freud, S. (1919/1997). "Pegan a un niño". En Obras Completas. Tomo 7. Madrid: Editorial Biblioteca Nueva. 
Lacan, J. (1956-1957). "Seminario 4: La relación de objeto." Traducción de Eric Berenger. Descargado el 21 de Junio de 2014 del sitio web: http://www. bibliopsi.org.

Poe, K. (2016). ¿Un método peligroso? Freud y el Moisés de Miguel Ángel. Claroscuro Cuadernos de Psicoanálisis, VivEros ediciones, 4, 117-130

Wilson, E. (2009). Contemporary film directors: Atom Egoyan. U.S.A: University of Illinois Press.

\section{Filmografía}

Griffiths, K. \& Freeman, D. (Productores), \& Egoyan, A. (Director). (1995). A portrait of Arshile. Inglaterra: BBC Television y ACE Arts Council of England.

Egoyan, A. \& Lantos, R. (Productores), \& Egoyan, A. (Director). (2002). Ararat. Francia/Canadá: Miramax.

Francis, M. (Director). Egoyan, A. \& Lantos, R. (Productores) (2003). The Making of Ararat. Francia/Canadá: Miramax.

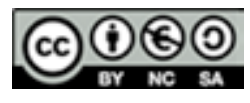

Esta obra está bajo una licencia de Creative Commons Reconocimiento

- NoComercial - CompartirIgual (by-nc-sa) 